\title{
Study Structural properties of Nanocomposite (polyvinyl Alcoholl (CdO/NiO) via Sol-Gel Method
}

Amatalkareem Mohammed Al-Jezbi ( $\sim$ 1amat.alkareem@gmail.com )

Research article

Keywords: Nickel Oxide, Cadmium Oxide, Sol-gel method, Nanocomposite, NiO/PVA, CdO/PVA

Posted Date: May 14th, 2021

DOl: https://doi.org/10.21203/rs.3.rs-498096/v1

License: (9) (i) This work is licensed under a Creative Commons Attribution 4.0 International License.

Read Full License 


\section{Abstract}

This study deals with the synthesis of some physical properties of (CdO/NiO) nanocomposite via Sol-Gel method and their antibacterial activities. The $\mathrm{NiO}$ and $\mathrm{CdO}$ nanoxides as well as the $\mathrm{CdO} / \mathrm{NiO}$ oxide mixture were prepared in five samples with different concentrations where the ratio of $\mathrm{CdO} / \mathrm{NiO}$ was [( 1 : $0),(3: 1),(1: 1),(1: 3),(0: 1)]$, by using the gel solution by means of a polyvinyl alcohol solution (PVA ). The samples were platelimb at $(500 \mathrm{C})$ for three hours. The structural properties of the prepared oxides resulting from the cracking process were studied. The XRD results showed the presence of pure cadmium oxide diffraction patterns in the sample (S 1 ) as well as pure nickel oxide in the sample (S 5 ), and confirmed the presence of the $\mathrm{CdO} / \mathrm{NiO}$ oxide mixture in the samples (S 2 , S 3 , S 4 ). The results of XRD also showed, through calculations, that the specific surface area increased with increasing granular size and decreased with decreasing granular size. XRD calculations also showed that the intensity of eruptions decreased as the granular volume increased and, inversely, increased with decreasing granular size.

\section{Full Text}

This preprint is available for download as a PDF. 